\title{
Espaço Comum de Ensino Superior da União Europeia, América Latina e Caribe (ECES - UEALC): Nova forma de incorporação dependente? ${ }^{1}$
}

Zacarias Gama*

Raquel Villardi**

\section{Resumo}

Três objetivos norteiam este texto que toma como objeto a construção do Espaço Comum de Educação Superior - União Europeia, América Latina e Caribe (ECES-UEALC): demonstrar que a imposição de uma racionalidade neoliberal aos sistemas de educação superior da região, por meio de processos de avaliação, visa superar crenças e procedimentos, e estandardizar e universalizar métodos e processos; destacar o processo de alinhamento das instituições de educação superior da América Latina e Caribe ao Espaço Europeu de Educação Superior - EEES; examinar o alcance do que pode ser uma nova forma de incorporação da América Latina e Caribe. A tese central que procura discutir considera que a construção do ECES-UEALC com a utilização de meios de conformação das universidades da região a determinados parâmetros e indicadores de qualidade apenas conformam-nas aos interesses dos países centrais da acumulação capitalista, e ao que está sendo chamado de sociedade do conhecimento.

Palavras chave: avaliação institucional. sistemas de educação superior. dependência acadêmica, ECES-UEALC.

\section{Introdução}

Os ajustes das políticas neoliberais na América Latina e Caribe, a partir dos anos 1980, colocaram em destaque a necessidade de modernizar as instituições

1 Os estudos para este texto contaram também com pesquisa de campo na Argentina e em Portugal, nos meses de Junho/Julho de 2011, financiamento FAPERJ, e estágio de pós-doutoramento na Universidade de Lisboa/IE, entre nov.2011 e abr. 2012 com financiamento CAPES.

* Pós-doutorado em Educação pelo Instituto de Educação da Universidade de Lisboa., Professor Associado da Universidade do Estado do Rio de Janeiro (UERJ). E-mail: zacarias_gama@yahoo.com.br.

** Doutora em Letras, UFRJ, Professora Associada da UERJ. E-mail: raquelvillardi@gmail.com. 
sociais, econômicas e administrativas, e superar certos fatores responsáveis pela lentidão do incipiente processo de reativação econômica desta região. Igual necessidade passou a ser a de avaliação delas com regularidade, conformando-os de acordo com certos indicadores de qualidade para efeito de comparabilidade nacional e internacional.

Os ministros de educação presentes à $1^{a}$ Conferência Ibero-americana de Educação - promovida pela Organização dos Estados Ibero-americanos (OEI), na cidade de Havana, em 1989 - preocupados com a lentidão, em face da revolução tecnológica (robótica, microeletrônica, engenharia genética e novos materiais), anteviam mudanças significativas na forma de organização do trabalho e na sua divisão internacional, como também na geopolítica mundial, "nas condições setoriais de produção, condições de vida e trabalho e no rol e funcionalidade da região ibero-americana" (ORGANIZACIÓN DE ESTADOS IBEROAMERICANOS, 1989).

Três anos mais tarde, as mesmas autoridades ou seus representantes, presentes à Conferência de Chefes de Governo e Estado (ORGANIZACIÓN DE ESTADOS IBEROAMERICANOS, 1992), sob a égide da Organização dos Estados Ibero-americanos, encomendaram ao Banco Mundial e ao Fundo Monetário Internacional (FMI) estudos e propostas concretas para mobilizar recursos financeiros para a América Latina e Caribe.

Os chefes de Estado e Governo, imbuídos desse afã reformista, certamente deixaram de avaliar a proposta de liquidação de aspectos negativos considerados crônicos: seriam, de fato, negativos? Para quem? O que pode ser considerado negativo para o Banco Mundial e o FMI seria igualmente para as sociedades e comunidades acadêmicas da região?

Não obstante, todos os aspectos relativos à dimensão e à abrangência deste reformismo, as políticas de avaliação da qualidade da educação superior e de acreditação de novos cursos despertam interesse especial porque, a despeito da positividade que possam ter, podem, em tese, se apresentar impregnadas de meios de conformação das universidades a determinados parâmetros, geralmente elaborados nos países centrais da acumulação capitalista, os quais tendem a adequá-las à economia do que está sendo chamado de sociedade do conhecimento. 
É evidente que toda sociedade produz os conhecimentos indispensáveis ao atendimento das suas necessidades e que, neste sentido, todas são sociedades de conhecimento. A diferença é que a sociedade do conhecimento em processo de formação na União Europeia tende a ultrapassar esta compreensão lato sensu. Ela seria decorrente da cultura digital, caracterizada por possibilidades ampliadas de controle, armazenamento, busca e acesso aos mais variados conjuntos de informações, o que transforma o conhecimento no principal ativo de países e organizações, no enfrentamento da competitividade globalizada. $\mathrm{O}$ capital e o seu atual processo sociometabólico visam à apropriação do conhecimento produzido nestas bases como mercadoria. Não se trata, pois, de produzir qualquer conhecimento - ou o conhecimento socialmente necessário, ou aquele que se coaduna à cultura que o produz, mas de realizar uma industrialização de conhecimentos com valor de mercado; de produzir conhecimento para fins de acumulação.

Para a realização deste trabalho teórico-conceitual, de caráter exploratório, nossas análises foram produzidas basicamente a partir de diversos documentos provenientes de organismos internacionais, destacando-se as Declarações e Compromissos firmados em Conferências de Chefes de Governo e Estado e de Ministros de Educação dos países membros da Organização dos Estados Ibero-americanos, e em Conferências de Chefes de Governo e Estado da União Europeia, América Latina e Caribe. Este trabalho tem origem nas preocupações dos membros do Grupo de Pesquisa que ora investiga a Avaliação das Instituições Públicas de Ensino Superior: a reconversão das universidades públicas nos marcos das políticas de ajustes e reestruturação do Estado - estudo comparativo Brasil, Portugal e Argentina.

Três objetivos norteiam as nossas reflexões. O primeiro se liga ao grande interesse em demonstrar que a imposição de uma racionalidade neoliberal aos sistemas latino-americanos e caribenhos de educação superior, por meio dos processos de avaliação institucional, tem a pretensão de superar crenças e procedimentos, e de estandardizar e universalizar métodos e processos. Esta racionalidade não é meramente funcional; as formas de trabalho que visam implementar são constituintes e diretivas do processo de produção de conhecimentos, de modo a alinhar os sistemas de educação superior da região aos mesmos processos utilizados nas instituições de pesquisa e ensino situadas nos países centrais, em particular na União Europeia. 
A expectativa condizente com esta racionalidade é a de que os nossos sistemas de educação superior possam adquirir maior amplitude e produtividade em suas finalidades de ensino, pesquisa e extensão. Pouco importa que nossas instituições, na correlação de poder com as situadas ao Norte do Equador, sejam mais frágeis; pouco importa, também, se isso implica em meios de colonização da nossa produção de conhecimentos; e pouco importa, por fim, se a dimensão do conhecimento produzido responde às necessidades e anseios da sociedade em que se insere.

O segundo, deriva da necessidade de destacar a existência, na região, de um processo de configuração de um grande espaço de educação superior diretamente alinhado ao Espaço Europeu de Educação Superior (EEES). Tal configuração tem sido exigência das Conferências Ibero-americanas de Educação promovidas pela Organização dos Estados Ibero-americanos, e mais efetivamente pelos encaminhamentos das conferências conjuntas da União Europeia, América Latina e Caribe que já produziram concretamente o Espaço Comum de Educação Superior União Europeia, América Latina e Caribe ECES -UEALC (EUROPEU PARLIAMENT, 1999).

Por último, urge que examinemos o que vem sendo desenhado para a região, em termos educacionais, científicos, tecnológicos e culturais, porque seu alcance parece estruturar uma nova forma de incorporação dependente da América Latina e Caribe, em processo de aceleração a partir dos anos 1990.

\section{A racionalidade neoliberal}

Há muito sabemos que o capitalismo tende a organizar a produção e a exploração do trabalho, e que isso, contudo, não constitui uma exclusividade sua. Toda produção é feita por indivíduos sociais para atender às necessidades de sua existência. A maior quantidade e qualidade de produtos, portanto, depende do nível de desenvolvimento das forças produtivas e das relações sociais. $\mathrm{O}$ processo histórico de desenvolvimento de tais forças e relações, em suas distintas fases, permite-nos distinguir diferentes formas de organização da produção e do trabalho pelas classes dominantes. Na Antiguidade e na Idade Média, as formas de organização foram escravistas e feudais. A partir do século XVIII, a moderna produção burguesa passou a ser realizada com o assalariamento da mão de obra e com maiores possibilidades técnicas para extrair a mais-valia e realizar a acumulação de capital. 
A racionalidade que o capitalismo impõe à produção e à exploração do trabalho para a sua realização torna-se cada vez mais dependente das ciências e das suas experimentações exatas e racionais. Friedrich Engels 1894 (ENGELS, 2007), em carta a Walther Borgius (Heinz Starkenburg), já chamou a atenção para o fato de que são as necessidades técnicas que fazem a ciência avançar, e não o contrário. Os exemplos que Engels nos fornece nesta carta são bem ilustrativos e trazem à luz o caso da hidrostática de Torricelli, criada para regular os fluxos d'água nas montanhas da Itália, nos séculos XVI e XVII. Nos dias atuais, há diversos outros exemplos. A necessidade de construir túneis para os trens subterrâneos exige constantemente o desenvolvimento de novas perfuratrizes, mais possantes e informatizadas; no campo da medicina, o avanço busca atender às necessidades das microcirurgias, de próteses e órteses, além de equipamentos computadorizados de diagnóstico.

Diversos outros exemplos poderiam ser dados se recorremos às ciências da farmácia, eletrônica, comunicação, etc. Chauí (2008) assinala que Adorno e Horkheimer, dois filósofos da Escola de Frankfurt, já haviam desenvolvido reflexões sobre tal racionalidade, descrevendo-a como instrumentalização da razão. Na perspectiva em que eles se situaram, o fim último da racionalidade é ser instrumento de domínio e controle da natureza e dos seres humanos para obter maior produtividade e, consequentemente, mais valia.

A racionalidade característica do processo sociometabólico do capital em bases neoliberais é surpreendente, e sua voracidade tende a abarcar tudo e todos, nem o campo da educação lhe escapa. O neoliberalismo, como é sabido, altera as estratégias de desenvolvimento ao imprimir formas de crescimento lideradas por exportações e vantagens competitivas. Busca, primordialmente, incorporar novas economias ao comércio mundial, pouco importando que sejam alteradas, profundamente, as relações sociais e a vida organizacional destas sociedades.

A regulação dos sistemas de educação na América Latina e Caribe, tanto quanto na União Europeia, abrangendo todos os níveis e modalidades, está sendo subsumida a esta ideia de racionalidade que tem como meta o maior rendimento e a maior produtividade definidas a partir de determinadas matrizes e parâmetros únicos. Entendemos a regulação no campo da educação, tal como Antunes (2006), isto é como um conjunto de padrões e regras que definem o funcionamento das instituições. 
A partir dos anos 1990, na América Latina e Caribe, tornou-se imperativo avaliar a qualidade e a oferta de cursos das diversas instituições de ensino básico e superior a partir de sistemas de gestão, avaliação e acreditação. Mas foi somente a partir de 1995 que todos esses sistemas passaram concretamente a se subordinar à mesma lógica e a se referenciarem à mesma matriz, isto é, ao Programa "Desenvolvimento de Sistemas Nacionais de Avaliação da Qualidade", que se tornou universal para a região na V Conferência Ibero-americana de Educação ocorrida em Buenos Aires (ORGANIZACIÓN DE ESTADOS IBEROAMERICANOS, 1995).

Esse Programa oferece a base de indicadores de qualidade sobre a gestão e avaliação da educação superior, necessidades e demandas, ofertas e assistência técnica, e capacitação de recursos humanos para instalar sistemas que atendam às necessidades regionais. Tal programa indica sobremaneira a necessidade de aprofundar e compartilhar experiências orientadas à formulação de políticas eficazmente estruturadas, de modo a atingir as metas educativas gerenciadas pela OEI.

Até 1995, somente dois sistemas de avaliação e acreditação das instituições de educação superior haviam sido criados, em 1990 e 1992, respectivamente, o Consejo Nacional de Universidades (CNU) da Nicarágua, e o Sistema Nacional de Acreditación da Colômbia (SNA). A partir daí, a prática atinge outros países, sendo generalizada a partir do ano 2000 , como demonstra o quadro a seguir.

\section{Quadro 1 - Sistemas de Avaliação e Acreditação das Universidades na América Latina e Caribe}

\begin{tabular}{|c|c|c|}
\hline País & Organismo & Data \\
\hline Nicarágua & Consejo Nacional de Universidades (CNU) & 1990 \\
\hline Colômbia & Sistema Nacional de Acreditación & 1992 \\
\hline Argentina & $\begin{array}{l}\text { Comisión Nacional de Evaluación y Acreditación Universitaria } \\
\text { - (CONEAU) }\end{array}$ & 1995 \\
\hline Uruguai & $\begin{array}{l}\text { Ministerio de Cultura y Educación/Agencia de Acreditación } \\
\text { de la Calidad de la Educación Superior }\end{array}$ & 1995 \\
\hline Costa Rica & $\begin{array}{l}\text { Sistema Nacional de Acreditación de la Educación Superior } \\
\text { (SINAES) }\end{array}$ & 1999 \\
\hline Cuba & Junta de Acreditación Nacional (JAN) & $1999-2000$ \\
\hline México & $\begin{array}{l}\text { Comités Interinstitucionales para la Evaluación de la Educaci- } \\
\text { ón Superior, A.C. (CIEES)/ (COPAES) }\end{array}$ & 2000 \\
\hline Peru & $\begin{array}{l}\text { Consejo Nacional para la Acreditación de Universidades } \\
\text { (CONAFU) }\end{array}$ & 2001 \\
\hline
\end{tabular}

(Continua) 


\begin{tabular}{|l|l|l|}
\hline $\begin{array}{l}\text { República } \\
\text { Dominicana }\end{array}$ & \multicolumn{2}{l}{$\begin{array}{l}\text { Asociación Dominicana para el Auto Estudio y la Acreditación } \\
\text { (ADAAC) / Ley de Educación Superior de la R. Dominicana }\end{array}$} \\
\hline Equador & $\begin{array}{l}\text { Consejo Nacional de Evaluación y Acreditación de la Educaci- } \\
\text { ón Superior (CONEA) }\end{array}$ & 2002 \\
\hline Venezuela & $\begin{array}{l}\text { Ministerio del Poder Popular para la Educación Superior } \\
\text { (MPPES); /Sistema de Evaluación Académica (SEA) }\end{array}$ & $2002-2007$ \\
\hline Bolívia & $\begin{array}{l}\text { Consejo Nacional de Evaluación y Acreditación de la Educaci- } \\
\text { ón Superior (CONAES) }\end{array}$ & 2003 \\
\hline Paraguai & $\begin{array}{l}\text { Agencia Nacional de Evaluación y Acreditación de la Educaci- } \\
\text { ón Superior (ANEAES) }\end{array}$ & 2003 \\
\hline Brasil & $\begin{array}{l}\text { Sistema Nacional de Avaliação da Educação Superior - SINA- } \\
\text { ES (CONAES) }\end{array}$ & 2004 \\
\hline Panamá & $\begin{array}{l}\text { Universidad de Panamá (UP) / Régimen de Certificación y } \\
\text { Recertificación }\end{array}$ & 2004 \\
\hline El Salvador & $\begin{array}{l}\text { Ministerio de Educación/Plan Decenal de Reforma Educativa } \\
\text { 1995 - 2005 }\end{array}$ & 2005 \\
\hline Chile & Comisión Nacional de Acreditación (CNA) \\
\hline
\end{tabular}

Fonte: Rede Ibero-americana para Acreditação da Qualidade da Educação Superior (RIACES)

Apenas considerando o imediatismo aparente do fenômeno, o esforço supranacional de reformar os sistemas de educação superior, coordenado pela OEI, integra o objetivo maior de promover e consolidar o desenvolvimento econômico e social sustentado e sustentável da região latino-americana e caribenha, alavancando sua inserção definitiva no mundo globalizado. Neste contexto, as instituições de educação superior da região demandariam reformas em todas as suas dimensões, a partir de uma nova racionalidade administrativa e produtiva.

O pensamento dialético, tal como desenvolvido por Marx, nos leva, entretanto, a examinar com mais rigor o que está sendo estruturado. O que justifica este exame, considerando os interesses das classes dominantes, é a pressa de reformar os sistemas de educação superior da região com o argumento de que lhes faltariam padrões de racionalidade adequados e atuais; daí que sua impregnação por novos padrões viria a elidir a permanência de elementos irracionais incoerentes e inconsistentes. $O$ ponto de partida supõe que estariam arraigados em determinadas crenças, procedimentos, atitudes e ações atrasadas. O imperativo de conformá-los com a utilização de fortes instrumentos de avaliação e acreditação institucional transcende os limites da ciência, transformando-se em uma ideologia arbitrária, racionalizada e desejada, sem ser necessária, a não ser para determinados fins específicos. 
Neste caso, a realidade latino-americana e caribenha concreta e definida pelas singularidades que a caracterizam deve ser compreendida em um sistema de determinações construído a partir de fora, ou, como Marx (1985, p. 16) poderia dizer: um sistema que é "produto da cabeça pensante que se apropria do mundo do modo que lhe é possível”. Segundo Chauí (2008, p. 237), Adorno e Horkheimer diriam que as forças que oprimem tal realidade, isto é, que a dominam, tornam-se manifestas quando defrontam o indivíduo com o universal e, graças à obra de poucos opressores, pode subjugar muitos outros indivíduos. O triunfo da racionalidade que se deseja impor está, aqui no caso, na submissão ao formalismo lógico e na obediência à razão imposta.

\section{Espaço Comum de Educação Superior - União Europeia, América Latina e Caribe (ECES - UEALC)}

A Conferência do Rio de Janeiro, com a participação de 47 chefes de Estado e de Governo da América Latina, Caribe e União Europeia, ocorrida em junho de 1999, colocou em pauta a construção de um projeto comum de associação estratégica inter-regional. Já na Declaração que resultou dessa conferência, nos Artigos 54, 61 e 63, ficou compromissado a criação do Espaço Comum de Ensino Superior - União Europeia, América Latina e Caribe, o ECES UEALC. Em Paris, no ano seguinte, na Conferência de Ministros de Educação da União Europeia, América Latina e Caribe, sobre ensino superior, com a participação da Comissão Europeia de Educação e representantes de 48 países, concretizou-se a criação do ECES-UEALC (MADEIRA, 2009).

O objetivo do ECES-UEALC é o de facilitar intercâmbios de conhecimento, transferências de tecnologia e mobilidade acadêmica de estudantes, professores, investigadores e pessoal administrativo, bem como articular formação, emprego e conhecimento científico sob a coordenação da França, Espanha, Brasil, México e São Cristóvão e Neves. Mais do que facilitar intercâmbios, deve harmonizar, futuramente, os sistemas de educação superior, de modo a que todas as universidades da região tenham equivalência de cursos, créditos acadêmicos e diplomas - titulações.

A ideia de criar um sistema latino-americano e caribenho universal, sem restrições de fronteiras entre as regiões da América Latina, Caribe e União Europeia, tem a sua matriz no Processo de Bolonha, que começou a adquirir materialidade a 
partir das declarações de Sorbonne (1998) e Bolonha (1999) (LIMA; AZEVEDO; CATANI, 2008). O Processo de Bolonha define os passos a serem dados pelos sistemas de ensino superior da União Europeia, para a construção de um único sistema de ensino superior continentalmente harmonizado.

Para Llovet (2011), esse processo, em sua essência, constitui um espaço universitário comum, em cujo âmbito são homologados todos os títulos conseguidos, desde que estejam submetidos às mesmas diretrizes e estandartes. Lima, Azevedo e Catani (2008, p. 10) também aceitam que o Processo de Bolonha implica em reformas institucionais, realizadas por cada governo nacional da União Europeia, com vistas a "conduzir ao estabelecimento efetivo do novo sistema europeu de educação superior". Madeira (2009, p. 35), porém, vai mais além: de seu ponto de vista está em causa não apenas a formação do Espaço Europeu de Educação Superior, "mas a criação de uma Europa do conhecimento em que a educação e a formação se posicionam como motores do crescimento e do desenvolvimento econômico". Para Silva (2011, p. 1011), o Processo de Bolonha visa a "reprodução das classes economicamente dominantes e a legitimação das elites políticas, científicas e culturais, através de mecanismos tecnocráticos de hierarquização e competitividade de universidades e centros de investigação [...]".

À semelhança do que está a ocorrer na União Europeia, em nossa região, as ações concretas para a criação do ECES-UEALC tornam análogas todas as universidades da América Latina e Caribe e, em consequência, tornam comparáveis os estudos realizados em qualquer delas. Com a sua concretização, estudantes e profissionais poderão se deslocar entre diferentes universidades e países da região, conforme suas conveniências e necessidades. Mesmo que estejam salvaguardadas algumas especificidades nacionais, a mobilidade esperada é crucial para o seu sucesso. O sucesso dessa mobilidade contribuirá para a integração harmoniosa da região latino-americana e caribenha; na União Europeia, contribuirá para a sua própria consolidação política.

Neste enquadramento, é difícil deixar de concordar com as observações feitas por Llovet (2011) porque, de fato, a existência de grandes espaços de educação superior, em princípio, não é uma ideia descabida. Da perspectiva de políticas compensatórias, há quem compreenda a cooperação acadêmica como um esforço conjunto para conseguir a "equidade educativa na educação superior, 
considerando os distintos grupos sociais pobres e excluídos"; a desigualdade existente é um problema regional que requer a cooperação dos países da região latino-americana e caribenha e de seus vínculos internacionais (MONROY; FLORES, 2009, p. 3). Qual sociedade nacional deixaria de querer seu sistema de ensino superior equivalente aos sistemas mais avançados e de reconhecimento internacional, em termos de conteúdos e diplomas de alto valor agregado? Qual haveria de desprezar a harmonização das estruturas do ensino superior, sob pena de ficar à margem da União Europeia que se constrói como "uma sociedade da ciência e do conhecimento e, mais concretamente ainda, a um espaço comum europeu de ciência e de ensino superior, com capacidade de atração à escala europeia e intercontinental?" (MINISTÉRIO DA CIÊNCIA, TECNOLOGIA E ENSINO SUPERIOR, 2012, p. 1).

No âmbito da região latino-americana e caribenha, seriam louváveis as saudações vigorosas feitas à criação do ECES-UEALC, bem como as que exaltam a sua articulação com o Espaço Europeu de Educação Superior. Qual país latino-americano caribenho abandonaria esta iniciativa concreta? Qual abdicaria da simples possibilidade de ter o seu sistema de educação superior fora desta harmonização estrutural das diferentes universidades da União Europeia, América Latina e Caribe? Em sã consciência, somente alguma ação equivocada poderia recusar esta integração. Imediatamente, ninguém se questionaria acerca de possíveis armadilhas que esta conexão poderia encobrir. As elites e os intelectuais orgânicos da região, que Florestan Fernandes (2009) considerou como dóceis ao controle externo, certamente bradariam a plenos pulmões contra quaisquer aversões dificultadoras ou impeditivas.

A realidade, porém, é desprovida de encantamentos e exige não deixar-se atrair ingenuamente. Llovet (2011) nos adverte dos reais perigos existentes. Em sua perspectiva, o Processo de Bolonha pouco oferece para além de uma "ideia exclusivamente administrativa, em nada favorável à dignidade da vida intelectual” (LLOVET, 2011, p. 189). Já vimos que, para Silva (2011), esse mesmo Processo serve para reproduzir as classes dominantes e as elites políticas, científicas e culturais europeias.

Raciocínio análogo pode ser aplicável à construção do ECES-UEALC. De igual modo, o seu critério primordial está fundado no ordenamento econômico e na rentabilidade mercantil das universidades, segundo a racionalidade neoliberal, o 
que significa preterir a produção autônoma de conhecimentos, a educação global dos estudantes e as carreiras humanísticas. Llovet (2011) admite que a nova universidade que surge do Processo de Bolonha - pautada pelo produtivismo, pela eficiência, pela eficácia e pela rentabilidade - tende a se distanciar dos antigos propósitos liberais da primeira metade do século XX; ela propende a especializarse e a vincular, com eficiência econômica e política, as carreiras e o mercado de trabalho. O saber humanístico fica secundarizado, ainda que - ou talvez, por isso mesmo - esteja na base da civilização e da formação do espirito de cidadania.

As críticas de Llovet (2011) não são abjetas, nem desprovidas de pertinência; ao contrário, ainda que se circunscrevam ao âmbito europeu, são de grande valia para pensarmos a região latino-americana e caribenha, em especial quando consideramos os laços históricos de dependência que nos unem à União Europeia. Que garantia a criação do ECES-UEALC efetivamente nos oferece, em termos de simetria entre os sistemas de educação superior participantes, sabendo-se, à partida, que a União Europeia e suas agências de financiamento estarão na base das reformas universitárias e dos seus sistemas de avaliação da qualidade? A sólida colaboração entre os países da América Latina, Caribe e União Europeia, nos termos em que está sendo proposta e tendo em conta os diferentes estágios de desenvolvimento dos países envolvidos, poderia se traduzir em controle externo do sistema de educação superior da região latinoamericana e caribenha? Como afiançar que os intercâmbios de estudantes, profissionais técnico-administrativos, docentes e pesquisadores podem garantir o desenvolvimento independente e autossustentado da região? Poderia o ECES-UEALC ser compreendido como um avanço avassalador do capitalimperialismo europeu, ponderando-se que os diversos sistemas de educação superior da América Latina e Caribe ressentem-se de requisitos básicos para evoluírem com autonomia e igualdade?

Florestan Fernandes nos dá as bases teóricas para pensarmos os nossos sistemas de educação superior nesta relação de "sólida colaboração" com os sistemas da União Europeia, face às suas condições estruturais e dinâmicas, ao assinalar a histórica "incapacidade dos países latino-americanos de impedir a sua incorporação dependente ao espaço econômico, cultural e político das sucessivas nações capitalistas hegemônicas" (FERNANDES, 2009, p. 21). Ora, considerando o quadro conjuntural das universidades públicas da região e nossas condições de trabalho e produção, é inevitável questionarmos se é 
possível haver simetria entre as universidades latino-americanas e caribenhas e as europeias? E que força estas nossas universidades têm para sobrepujar, pelos seus próprios esforços, as pressões e as formas de controles externos?

\section{Nova forma de incorporação dependente da América Latina e Caribe?}

Florestan Fernandes (2009, p. 22) evidenciou quatro tipos de dominação externa na história da América Latina, "experimentados por quase todas as nações" da região. São formas de dominação e exploração que abrangeram a ocupação militar, econômica e jurídico-política dos territórios e das suas populações, segundo a vontade e o poder das Coroas de Espanha e Portugal: i) forte controle comercial dos negócios ligados à exportação e importação; ii) subsunção da economia, sociedade e cultura; iii) "incorporação maciça e direta de algumas fases dos processos básicos de crescimento econômico e desenvolvimento sociocultural"; iv) instalação de grandes empresas montadoras em territórios nacionais, nos campos das indústrias leves e pesadas, na fase do chamado capitalismo corporativo ou monopolista.

Nestes tempos de globalização, as formas de dominação enunciadas por Fernandes têm adquirido outras características, com grandes transformações nas perspectivas de organização e atuação, o que não implica, concretamente, o congelamento das anteriores.

O Brasil, em especial a partir dos anos 1990, década distinguida pela globalização e liquidez internacional, conseguiu criar "as bases materiais e ideológicas da nova virada do desenvolvimento e da política externa", segundo afirmações de Fiori (2007, p. 239). Esta situação permite ao Brasil diferenciar-se do conjunto dos países da região latino-americana e caribenha, com inclusão, destaque e sustentação no debate que se trava na América do Sul, "sobre uma nova posição internacional do continente e, em particular, sobre a redefinição da hegemonia hemisférica dos Estados Unidos" (FIORI, 2007, p. 239). Este autor chama a atenção para as forças ou atores que, mesmo em um cenário favorável a uma nova posição do Brasil, promovem e tentam afirmar uma opção liberal e subalterna, "uma espécie de cosmopolitismo de cócoras" (FIORI, 2000, p. 12).

Outra força é exercida por uma elite econômica que transita nos circuitos financeiros internacionais e se submete à tutela estrangeira. A importância de ressaltar as forças 
e atores evidenciados por Fiori é sua continuidade histórica; são as mesmas há muito já evidenciadas por estudiosos do Capitalismo Dependente e da Dependência Econômica da América Latina (SANTOS, 2000; BAMBIRRA, 2012; MARINI, 1979). Estes estudiosos foram precisos na identificação dos interesses particularistas das nossas elites e das suas frações, cujos integrantes continuam, ainda hoje, a criar as condições internas para a dominação externa. A concepção e a materialização do ECES-UEALC inscrevem-se neste mesmo enquadramento de subordinação dependente, desenvolvido pelas elites latino-americanas e caribenhas. Mas qual o seu impacto para o desenvolvimento atual e futuro da região?

A resposta dessa questão, além de não ser fácil, impõe ser pensada real e concretamente se queremos chegar a uma síntese. À partida, a sua construção carece ser plena de historicidade, abordando-se, inicialmente, determinadas categorias tidas como simples para apreender a nova conformação dos sistemas de educação superior na região latino-americana e caribenha, em suas relações com o sistema de educação superior da União Europeia. As necessidades da região e os valores de troca produzidos pelas suas universidades podem ser o ponto de partida.

Posto isso, é preciso, então, identificar as necessidades no campo da educação superior latino-americana e caribenha. Desde Marx (1985), é sabido que a necessidade é o ponto a partir do qual todo o processo de produção ocorre e se renova. A necessidade de novos conhecimentos, com alto valor agregado, é a atual necessidade da América Latina e Caribe. Na perspectiva da sociedade do conhecimento, as universidades da região, de fato, precisam deixar de se colocarem à margem do desenvolvimento econômico-social, como historicamente ocorreu até os anos 1960, no Brasil, em particular; também precisam abandonar o lugar de distribuição de títulos de bacharéis, como antes dos anos 1960, ou o de simples qualificadoras de mão de obra fundadas na Teoria do Capital Humano, tal como nos anos 1960 e 1970. É imperativo que assumam centralidade no processo de produção de novos conhecimentos, em todas as áreas, como fator estratégico de desenvolvimento socioeconômico da região, ou seja, como instituições socialmente referenciadas, nas quais se desenvolve uma ciência socialmente referenciada, ou ainda, instituições referenciadas na emancipação da sociedade.

As instituições de ensino superior necessitam, então, evoluir como produtoras de bens de produção - conhecimentos sociais, culturais, científicos e tecnológicos, assim como inovações -, plenas de valor de uso e de troca, com alto valor 
agregado, direcionando-se para a busca de respostas às questões sociais que se impõem ao país, à região e ao planeta. Conforme nos indica é relevante o papel das universidades para o desenvolvimento nacional. Num contexto de sociedade do conhecimento, a produção societária de conhecimentos "passa a depender cada vez mais do domínio das formas de pensamento adquiridas por procedimentos educativos sistemáticos do tipo escolar".

Contudo, é preciso que no ECES-UEALC a produção de conhecimentos estratégicos para a sociedade e a economia consiga se realizar, mas sem estar subordinada a determinações e interesses exógenos. A sujeição dependente, pelo menos em tese, tende a reduzir as universidades da região à produção de conhecimentos básicos para uma posterior agregação de valor nos centros mundiais mais dinâmicos da educação superior. Esse é um risco real e potencial a ser evitado.

A análise de um ranking internacional, de 2011, demonstra que nenhuma universidade da América Latina e Caribe se destaca entre as cem primeiras colocadas. No ranking divulgado pela QS World University Rankings (2011), indicando as posições das 500 melhores universidades do mundo, é evidente a hegemonia das universidades da Europa, Estados Unidos, Japão e Austrália. As melhores universidades latino-americanas situam-se muito abaixo das cem melhores, como é o caso, por exemplo, das universidades do México - UNAM e de São Paulo - USP (empatadas em $169^{\circ}$ lugar), de Campinas - UNICAMP $\left(235^{\circ}\right)$, de Buenos Aires - UBA $\left(270^{\circ}\right)$, Austral - UA $\left(353^{\circ}\right)$, Federal do Rio de Janeiro UFRJ $\left(381^{\circ}\right)$, PUC - Santa Maria $\left(388^{\circ}\right)$, de Los Andes Colômbia e Federal de São Paulo - UNIFESP $\left(401^{\circ}\right)$. Tal ranking, no entanto, construído a partir de paradigmas exógenos, além de se estabelecer sobre parâmetros diferenciados de condições de trabalho e produção, com ponderações diferentes para a América Latina e Caribe, desconsidera os impactos do patrimônio imaterial das nossas instituições sobre os processos de formação humana e de produção de conhecimento. Esse e outros rankings estrangeiros servem pouco como referenciais para um processo de integração interinstitucional - ao menos em âmbito latino-americano e caribenho.

A necessidade imediata das universidades da América Latina e Caribe deve ser a de garantir condições objetivas em todas as suas dimensões - ensino, pesquisa, extensão e administração - para satisfazer as expectativas da sociedade em que se inserem sem, no entanto, se reduzirem às "estreitas percepções empresariais da 'sociedade do conhecimento", tal como tem sido recomendado por Mala Singh 
(2005, p. 49). Também precisam ser autossustentáveis e autônomas, para vencer as limitações locais, de ordem política, social e econômica, e para que possam produzir toda gama de conhecimentos, inclusive das áreas consideradas, pelos paradigmas externos, menos nobres. Singh (2005), a esse respeito, propõe que as universidades abram os seus próprios caminhos para atender às demandas da sociedade e da sociedade do conhecimento, mas que permaneçam coerentes às suas culturas locais. É fácil concordar com essa autora quando afirma que as universidades precisam aumentar o acesso de grupos de estudantes até então excluídos, melhorando a qualidade dos serviços prestados, conservando-se "como espaço destinado ao pensamento crítico e reflexivo" (SINGH, 2005, p. 50).

\section{Considerações finais}

Os governantes e demais autoridades responsáveis pelas políticas públicas de educação superior da América Latina e Caribe pouca dúvida deixam a respeito da decisão de alinhar seus sistemas de educação aos da União Europeia. Os compromissos e protocolos assumidos em conferências e mesas de negociações, via de regra, deixam de ser discutidos com a sociedade e são transformados em políticas públicas, editadas de cima para baixo, para modernizar nossos sistemas de ensino superior. O que caracteriza tais práticas é o que Fiori denominou de uma espécie de cosmopolitismo de cócoras, que equivaleria ao irônico complexo de vira-lata, cunhado pelo dramaturgo Nélson Rodrigues. $\mathrm{O}$ fato é que, queiramos ou não, qualquer que seja a adjetivação dada a essas práticas, elas são criadoras das condições objetivas de incorporação dependente dos países às estruturas espoliantes do capital.

Sem tal complexo, todos nós gostaríamos de ver nossas universidades trabalhando em plenitude, produzindo conhecimento, buscando, na inovação tecnológica, alternativas para questões sociais prementes, pesquisando, participando dos desafios enfrentados pelas comunidades em que se inserem, formando sujeitos históricos, descobrindo e divulgando pesquisas, criando e mostrando sua arte e sua cultura, abrindo os seus muros a quem dela necessita e à sociedade que a sustenta, devolvendo, sob a forma de formação sólida de seus jovens e de novos conhecimentos, o investimento social que se faz nela.

As universidades brasileiras, em especial, têm encampado, nos últimos anos, o trabalho de transformação social que lhes compete fazer, com uma significativa 
ampliação da população escolarizada, e com a implantação, sucessiva e paulatina, de mecanismos de acesso diferenciados. A compreensão de que a desigualdade consiste em tratar igualmente os desiguais deu origem à adoção de procedimentos de discriminação positiva, fazendo a universidade brasileira se descolar, a pouco e pouco, de seu viés elitizante, tornando-a mais inclusiva e mais plural.

Buscar alcançar posições de destaque, compatíveis com as das universidades mais bem colocadas nos rankings internacionais, ainda que a partir de critérios exógenos, pode ser uma aspiração, mas não pode ser a meta prioritária de instituições de países periféricos, sobre as quais recaem condições diferenciadas de trabalho, além de compromissos explícitos com a sua população, os quais não podem ser negligenciados.

O produtivismo a que já estamos sendo submetidos traz em si duas consequências. A primeira é que, em busca de alinhamentos pautados por determinados indicadores de qualidade exógenos, continuamos a deixar em plano inferior, muitas vezes, a nossa obrigação com a construção de uma sociedade latino-americana e caribenha comprometida com o desenvolvimento social e com a equidade. A segunda é que, ao permitirmos que a nossa produção acadêmica seja pautada pelo modelo que responde às necessidades dos países centrais, estamos apenas produzindo conhecimentos científicos, tecnológicos e inovadores para a agregação de valores em outras paragens - ou seja, nos inserimos em uma divisão internacional de produção de conhecimentos como produtores de conhecimentos básicos, praticamente repetindo a lógica da dependência econômica, agora sob o formato de dependência acadêmica.

Nesse cenário em construção, o trânsito, em si, de estudantes e profissionais, bem como de conhecimentos produzidos em diferentes instituições estrangeiras, nos exporia a lidar com a diferença, mas não se constituiria, por si só, a favor do desenvolvimento de um modelo de universidade nacional socialmente referenciada, comprometida com a disseminação de seu trabalho na integralidade do corpo social; uma universidade cuja pauta não refletiria o autocentramento da elite. A expectativa desse trânsito nas bases em que está sendo pensado apenas poderia nos levar de volta aos rankings internacionais, porém, mais uma vez, poderíamos cair no engodo de nos fixarmos em parâmetros marcados pela racionalidade neoliberal que, tão somente, interessa aos países centrais... Em nosso entendimento, não precisa ser assim; não deve e não pode ser assim. 
A modelagem de sistemas de avaliação que considerassem, além dos aspectos sociais, nossas especificidades e nossa cultura poderia ser uma saída. Mas dois problemas se interpõem a essa possibilidade. O primeiro é a parcela da elite acadêmica que, ligada ao processo, vê, neste atrelamento, novas formas de projeção internacional, o que lhe permitiria atingir status semelhantes aos dos colegas de outros países. Essa tese está de acordo com Florestan Fernandes, que admite que a dependência seja construída a partir de dentro, pelas próprias elites.

$\mathrm{O}$ segundo se liga às regulações supranacionais: os inúmeros protocolos e tratados, assinados por nossas autoridades nacionais a partir de 1999, impõem, sem nenhum debate nas arenas políticas nacionais, determinações externas. Tais compromissos, por sua vez, se desdobraram num furor avaliativo que é, hoje, a marca das nossas políticas públicas de educação. Avaliações centralizadas, quantitativas, padronizadas, cujo desdobramento é o estabelecimento de novas metas e a realização de outras novas avaliações centralizadas, quantitativas, padronizadas... Foco único e exclusivo na informação - cenário ideal para a formação de sujeitos divorciada da conquista da autonomia.

Se estamos, hoje, na transição para uma universidade operacional, como aponta Chauí (2001), cabe a nós buscar mecanismos para escapar da armadilha que nos colocará, se efetivada, definitivamente na periferia. Um ECES - UEALC, pensado e implantado com a lógica de fortalecer a produção acadêmica regional, criado em conformidade com as necessidades da região, talvez seja uma alternativa consistente para evitar novas formas de incorporação dependente.

As instituições latino-americanas e caribenhas, de fato, precisam se tornar mais flexíveis para aceitar estudos realizados fora de suas salas de aula e laboratórios de pesquisas, reconhecendo a validade de formações e investigações realizadas em outros contextos. Paralelamente, é necessário buscar, com outros atores, a construção cooperativa de novos procedimentos de avaliação que contemplem a consolidação de uma autonomia pedagógica e científica. O processo em curso, no entanto, deriva de uma visão hegemônica de mundo; uma visão que na empurra para a equalização rasa de objetivos, de processos, de pessoas; uma visão que somente se concretiza na medida em que ainda não aprendemos a lidar com as nossas diferenças e a consolidar a nossa independência regional. 


\section{Referências}

ANTUNES, F. Governação e Espaço Europeu de Educação: regulação da educação e visões para o projeto 'Europa'. Revista Crítica de Ciências Sociais, Portugal, n. 75, p. 63-93, 2006.

BAMBIRRA, V. O Capitalismo dependente Latino-americano. Florianópolis: Insular, 2012.

CHAUÍ, M. Convite à Filosofia. São Paulo: Ática, 2008.

CHAUÍ, M. Escritos sobre a universidade. São Paulo: Editora da Unesp, 2001.

ENGELS, F. Carta de Friedrich Engels a Walther Borgius (Heinz Starkenburg), 25 de Janeiro de 1894. In: SVERDLOV, M. Cartas de Karl Marx e Friedrich Engels. Paris: Editora da UCR J, 2007. Disponível em: $<$ http://www.scientific-socialism. de/FundamentosCartasMarxEngels250194.htm>. Acesso em: 1 mar. 2013.

EUROPEU PARLIAMENT. América Latina/Caribe/Unión Europea: primera Cumbre declaración de Rio. Brussels, 1999. Disponível em: <HTtP://www. EUROPARL.EUROPA.EU/DELEGATIONS/NONEUROPE/IDEL/D12/DOCS/CUMBREDERIO/ DECLARACIONFINALES.HTM\#>. Acesso em: 1 mar. 2013.

FERNANDES, F. Capitalismo dependente e classes sociais na América Latina. São Paulo: Global, 2009.

FIORI, J. L. O cosmopolitismo de cócoras. Estudos Avançados. São Paulo, v. 14, n. 39, p. 21-32, maio/ ago. 2000 Disponível em: <http://www.scielo.br/ scielo.php?script=sci_arttext\&pid=S0103-40142000000200004\&lng=en\&nrm =iso $>$. Acesso em: 1 mar. 2013.

FIORI, J. L. O poder global. São Paulo: Boitempo, 2007.

LIMA, L. C.; AZEVEDO, M. L. N. de; CATANI, A. M. O processo de Bolonha, a avaliação da educação superior e algumas considerações sobre a Universidade Nova. Revista da Avaliação da Educação Superior. Campinas, v. 13, n. 1, p. 7-36, 2008. 
LLOVET, J. Adiós a la universidad: el eclipse de las humanidades. Barcelona: Galaxia Gutenberg, 2011.

MADEIRA, A. I. O ensino superior da Europa e sua relação com a América Latina: a cooperação entre Portugal e Brasil. Revista Brasileira Política e Administração da Educação. Recife, v. 25, n. 1, p. 33-60, jan./abr. 2009.

MARINI, R. M. El ciclo del capital en la economía dependiente. In: OSWALD, U. Mercado y dependencia. México: Nueva Imagen, 1979.

MONROY, G. V.; FLORES, R. P. Políticas compensatorias para la equidad en la educación superior en América Latina en el marco de la cooperación académica del MERCOSUR y de la Unión Europea. In: CONGRESO INTERNACIONAL RETOS Y EXPECTATIVAS DE LA UNIVERSIDAD MÉXICO, 9., 2009, México. Trabalhos apresentados... México: Instituto Politécnico Nacional CFIE, 2009.

MARX, K. G. Lineamentos fundamentales para la crítica de la economia política: 1857-1858. México: Fondo de Cultura Económica, 1985.

MINISTÉRIO DA CIÊNCIA, TECNOLOGIA E ENSINO SUPERIOR. Direção Geral do Ensino Superior. DGES. O Processo de Bolonha: um longo e complexo processe de maturação. Lisboa, 2012. Disponível em: $<$ http://www.dges.mctes.pt/DGES/pt/Estudantes/Processo+de+Bolonha/ Processo+de+Bolonha/>. Acesso em: 1 mar. 2013.

ORGANIZACIÓN DE ESTADOS IBEROAMERICANOS. I Conferencia Iberoamericana de Educación: conclusiones de la reunión sobre educación, trabajo y empleo. Habana, 1989. Disponível em: $<$ http://www.oei.es/icie.htm>. Acesso em: 1 mar. 2013.

. Segunda Cumbre Iberoamericana de Jefes de Estado y de Gobierno. Declaración de Madrid. Madri: OEI, 1992. Disponível em: <http://www.oei.es/ iicumbre.htm>. Acesso em: 1 maio 2011.

.V Conferencia Iberoamericana de Educación. Buenos Aires, 1995.

Disponível em: <http://www.oei.es/vcie.htm>. Acesso em: 1 mar. 2013. 
QS WORLD UNIVERSITY RANKINGS: trusted by students since 2004. Austrália, 2011. Disponível em: <http://productionfiles. qs.s3.amazonaws. com/2714/proof_v1_2714.pdf $>$. Acesso em: 1 abr. 2013.

SANTOS, T. dos. A teoria da dependência. 1. ed. Rio de Janeiro: Editora Civilização Brasileira, 2000. v. 1.

SAVIANI, D. O lugar da educação no desenvolvimento nacional. In: GAMA, Z.; BRUNET, E.; FRIGOTTO, G.; AMARAL, R.; LOPES, L. C. B. (Org). Seminário Desenvolvimento e Educação: qual Desenvolvimento e Educação para qual Sociedade? Rio de Janeiro: Fundação CEPERJ, 2010.

SILVA, M. C. Ensino superior, desigualdades sociais e processo de Bolonha: do velho ao novo elitismo na 'Sociedade do Conhecimento'. Travessias 10. Lisboa, jul. 2011. Disponível em: <http://www.fenprof.pt/download/fenprof/m_html/ mid_180/anexos/manuel_carlos_silva__intervencao.pdf $>$. Acesso em: 1 abr. de 2013.

SINGH, M. Universidades e sociedade: compromissos de quem?. In: UNESCO. Sociedade de conhecimento versus economia de conhecimento: conhecimento, poder e política. Brasília, DF: UNESCO, 2005.

\section{Common Space of Higher Education of the European Union, Latin America and the Caribbean (ECES - UEALC): new form of dependent incorporation? \\ Abstract}

Three objectives guide this paper which is focused on the construction of the Common Space of Higher Education - the European Union, Latin America and the Caribbean (CSHE-EUALC): to demonstrate that the imposition of a neoliberal rationale over the higher education systems in the region, via evaluating processes, aims to overcome beliefs and procedures, and to standardize and universalize methods and processes; to highlight the aligning 
process of higher education institutions from Latin American and Caribbean to the European Higher Education Area; to examine the scope of what may be a new form of incorporation of Latin America and the Caribbean. The central thesis to be discussed considers that the construction of the CSHE-EUALC with the use of means of subordination of the regional universities with use of some parameters and quality indicators are aligned to the interests of core countries of capitalist accumulation, and what is being called knowledge society.

Keywords: institutional assessment. higher education systems. academic dependency. ECES-UEALC.

\section{Espacio Común de Rnseñanza de la Unión Europea, América Latina y el Caribe (ECES-UEALC): nueva forma de incorporación dependiente?}

\section{Resumen}

Tres objetivos guían este texto, centrado en la construcción del Espacio Común de Educación Superior - la Unión Europea, América Latina y el Caribe (ECESUEALC): demostrar que la imposición de una racionalidad neoliberal a los sistemas de educación superior de la región, a través de procesos de evaluación de las instituciones, tiene como objetivo superar creencias, procedimientos y métodos con la finalidad de universalizar y estandarizar los procesos; poner de manifiesto la existencia de un proceso de adaptación de las instituciones de educación superior al Espacio de Educación Superior Europea; analizar el alcance de lo que puede ser una nueva forma de incorporación dependiente. La tesis central discute si la construcción de la ECES-UEALC se ajusta a los intereses de los países centrales de la acumulación capitalista y a lo que se suele llamar sociedad del conocimiento.

Palabras clave: Evaluación institucional. Sistemas de educación superior. Dependencia académica. ECES-UEALC. 